NASA/TM-2001-210766

Satellite Communications for Aeronautics Applications-Technology Development and Demonstration

Robert J. Kerczewski, Douglas J. Hoder, and Robert J. Zakrajsek

Glenn Research Center, Cleveland, Ohio 
Since its founding, NASA has been dedicated to the advancement of aeronautics and space science. The NASA Scientific and Technical Information (STI) Program Office plays a key part in helping NASA maintain this important role.

The NASA STI Program Office is operated by Langley Research Center, the Lead Center for NASA's scientific and technical information. The NASA STI Program Office provides access to the NASA STI Database, the largest collection of aeronautical and space science STI in the world. The Program Office is also NASA's institutional mechanism for disseminating the results of its research and development activities. These results are published by NASA in the NASA STI Report Series, which includes the following report types:

- TECHNICAL PUBLICATION. Reports of completed research or a major significant phase of research that present the results of NASA programs and include extensive data or theoretical analysis. Includes compilations of significant scientific and technical data and information deemed to be of continuing reference value. NASA's counterpart of peerreviewed formal professional papers but has less stringent limitations on manuscript length and extent of graphic presentations.

- TECHNICAL MEMORANDUM. Scientific and technical findings that are preliminary or of specialized interest, e.g., quick release reports, working papers, and bibliographies that contain minimal annotation. Does not contain extensive analysis.

- CONTRACTOR REPORT. Scientific and technical findings by NASA-sponsored contractors and grantees.
- CONFERENCE PUBLICATION. Collected papers from scientific and technical conferences, symposia, seminars, or other meetings sponsored or cosponsored by NASA.

- SPECIAL PUBLICATION. Scientific, technical, or historical information from NASA programs, projects, and missions, often concerned with subjects having substantial public interest.

- TECHNICAL TRANSLATION. Englishlanguage translations of foreign scientific and technical material pertinent to NASA's mission.

Specialized services that complement the STI Program Office's diverse offerings include creating custom thesauri, building customized data bases, organizing and publishing research results ... even providing videos.

For more information about the NASA STI Program Office, see the following:

- Access the NASA STI Program Home Page at http://www.sti.nasa.gov

- E-mail your question via the Internet to help@sti.nasa.gov

- Fax your question to the NASA Access Help Desk at 301-621-0134

- Telephone the NASA Access Help Desk at 301-621-0390

- Write to: NASA Access Help Desk NASA Center for AeroSpace Information 7121 Standard Drive Hanover, MD 21076 
NASA/TM-2001-210766

\section{Satellite Communications for Aeronautics Applications-Technology Development and Demonstration}

Robert J. Kerczewski, Douglas J. Hoder, and Robert J. Zakrajsek Glenn Research Center, Cleveland, Ohio

Prepared for the 2001 Aerospace Conference sponsored by the Institute of Electrical and Electronics Engineers Big Sky, Montana, March 10-17, 2001

National Aeronautics and Space Administration

Glenn Research Center 
Trade names or manufacturers' names are used in this report for identification only. This usage does not constitute an official endorsement, either expressed or implied, by the National Aeronautics and Space Administration.

Available from

NASA Center for Aerospace Information

7121 Standard Drive

Hanover, MD 21076

Price Code: A03
National Technical Information Service 5285 Port Royal Road Springfield, VA 22100 Price Code: A03

Available electronically at http://gltrs.grc.nasa.gov/GLTRS 


\title{
Satellite Communications for Aeronautics Applications-Technology Development and Demonstration
}

\author{
Robert J. Kerczewski, Douglas J. Hoder, and Robert J. Zakrajsek \\ National Aeronautics and Space Administration \\ Glenn Research Center \\ Cleveland, Ohio 44135
}

\begin{abstract}
The National Aeronautics and Space Administration (NASA) is performing research and development to improve the safety and increase the capacity of the National Airspace System (NAS). Improved communications, especially to and from the aircraft flight deck, has been identified as an essential enabling technology for future improvements to the air traffic management system and aviation safety.
\end{abstract}

NASA's Glenn Research Center is engaged in research and development of satellite communications technologies for aeronautical applications. A mobile aero terminal has been developed for use with $\mathrm{Ku}$ Band commercial communications satellites. This experimental terminal will be used in mobile ground and air-based tests and demonstrations during 2000-2004.

This paper will describe the basic operational parameters of the $\mathrm{Ku}$ Band aero terminal, the communications architecture it is intended to demonstrate, and the key technology issues being addressed in the tests and demonstrations. The design of the Ku Band aero terminal and associated ground testbed, planned tests and demonstrations, and results to date will be presented.

\section{INTRODUCTION}

Substantial growth in aviation continues to put increased pressure on both the capacity and safety of the national and global airspace systems. In the United States, the number of commercial flight delays and cancellations in the summer of 2000 exceeded the records set in the summer of 1999. The problem of constrained airspace will continue to grow as aviation traffic increases.
The aviation accident rate has remained approximately constant for the last 30 years. As the number of flights increases, the total number of accidents will also increase. It is projected that, on average, a major aviation accident could occur every week within 20 years if the accident rate is not reduced.

NASA has established two major research and development programs to address these issues. The Aviation System Capacity Program (ASCP) [1] is addressing many research issues dealing with improving the ability of the NAS to increase the overall throughput of aviation traffic. The Aviation Safety Program (AvSP) [2] is addressing a range of issues affecting the fatal aviation accident rate. For both programs, studies have indicated that a critical component needed to enable the fielding of new systems to address capacity and safety concerns is information dissemination. Improved communications systems and technologies necessary to implement strategies being developed in ASCP and AvSP are being developed and tested by NASA's Glenn Research Center.

Current communications systems within the NAS lack the bandwidth to allow implementation of planned future air traffic management systems and aviation safety improvements. The Federal Aviation Administration (FAA) is planning a series of upgrades to the current communications links employed for air traffic control and other critical aviation communications links, as defined by the FAA's National Airspace System Architecture Version 4.0 [3]. The primary improvements will consist of upgrades to the current analog voice based very high frequency (VHF) communications, which use ground based transmitters operating over $25 \mathrm{kHz}$ channels. Future VHF links will be digital data links, providing data and combined voice and data capabilities. The NAS 4.0 architecture calls for full phase-in of the digital data links by 2015 . 
NASA's research into capacity and safety enhancing aviation systems is focusing on advanced, integrated, data intensive systems, particularly important when considering radical new methods of air traffic management which are believed necessary to allow continued growth in aviation far into the future. These methods lie beyond the planning horizon of the NAS 4.0, and hence the communications systems currently being developed for installation within the next decade will still be inadequate to provide the capacity and connectivity required to support these advanced new systems. Further constraining the communications capacity is the limited availability of VHF spectrum for aeronautical uses.

The NASA Glenn Research Center is considering future aeronautical communications system architectures that can address the capacity and connectivity constraints Although VHF systems will be used far into the future, due to the considerable infrastructure investment and proven reliability, a hybrid system consisting of ground-

\section{APPLYING SATELLITE COMMUNICATIONS TO AERONAUTICS - APPROACHES AND ISSUES}

Two major studies performed for the NASA Glenn Research Center looked at communications requirements and approaches for air traffic management and weather information dissemination $[4,5]$. Several key conclusions from these studies support the concept of satellite communications as a major communications link in future aeronautical communications systems. Among these conclusions: satellite communications has many characteristics which are ideally suited to the aeronautical mobile environment; satellite communications has the necessary bandwidth to remove communications system constraints for the future NAS; broadband satellite communications can provide revenue generating passenger services which can pay for system installation and operation, providing simultaneous communications capacity for other aeronautical needs; and satellite communications can fill

\section{Ground Systems Air / Ground Comm Aircraft}

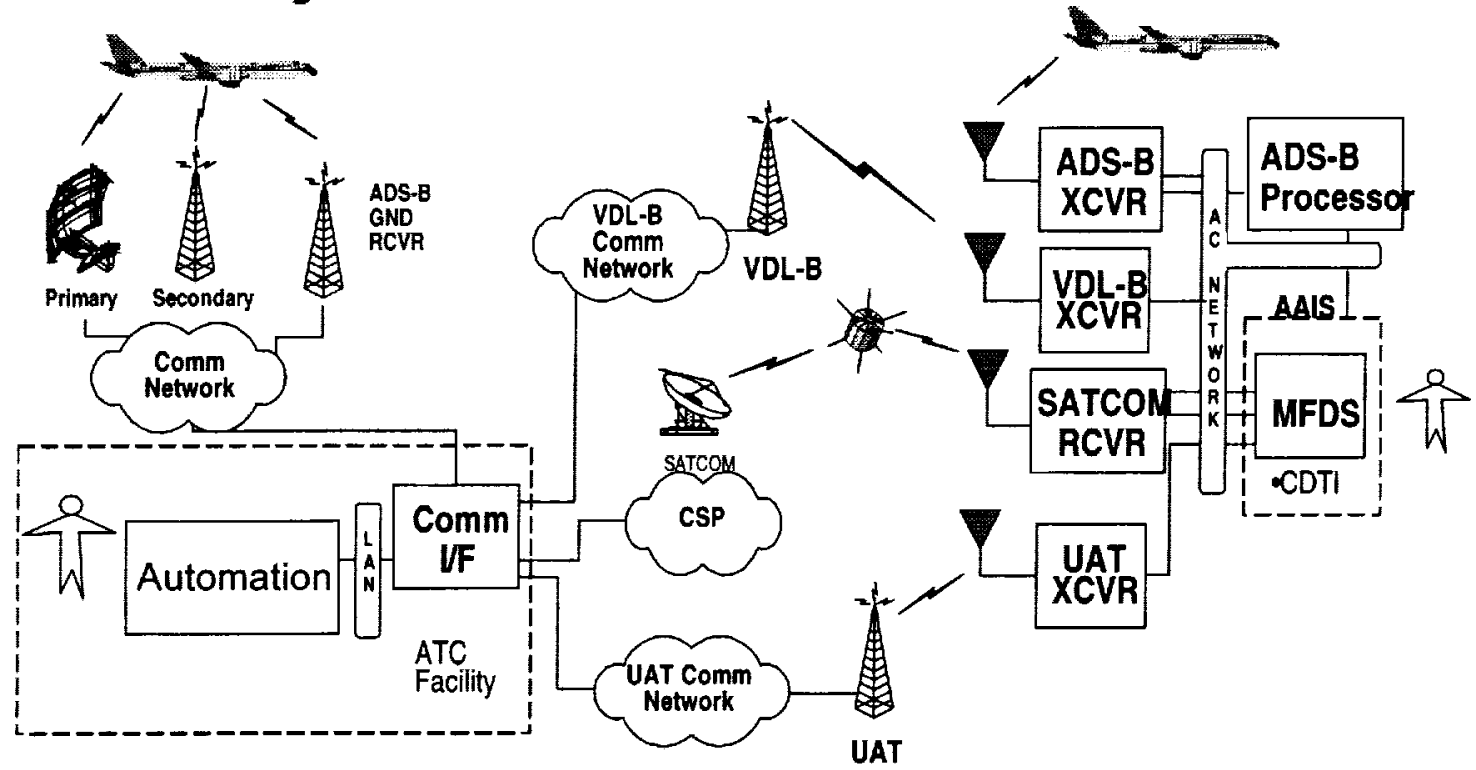

Figure 1-A possible architecture for delivery of aeronautical traffic information services.

based and space-based communications links has the best potential for addressing the needs of future aeronautical communications. The space-based part of the architecture, which consists of communications links through satellites from aircraft-to-ground, ground-toaircraft, and aircraft-to-aircraft will require considerable development, experimentation and demonstration, and is the primary focus of the NASA Glenn aeronautical communications work described in this paper. coverage and service gaps that terrestrial systems cannot fill, and can operate effectively in an integrated hybrid fashion.

An example of an aeronautical communications system architecture consisting of a hybrid space/terrestrial approach is shown in Figure 1 [5]. In this suggested architecture, a satellite communications link provides a portion of traffic information services communications, while ground based services collect position location and other information broadcast from aircraft and transmit local traffic information. 
Other types of aeronautical services can also benefit from satellite communications providing either all or a portion of communications requirements, and there are similar architectures proposed for these services which include a hybrid of space and terrestrial communications links. Satellite communications can fill significant coverage gaps that terrestrial systems are physically unable to fill, such as remote geographic regions, oceanic regions, and mountainous regions where terrain can block groundbased line-of-sight paths. Satellites also have the advantage of being able to provide coverage at all altitudes and can broadcast to large geographic areas.

However, despite many recent technological advances in satellite communications, application to aeronautical needs has not been a major consideration. Hence, much development is necessary to apply satellite communications hardware designed for fixed groundbased systems to a mobile aeronautical environment. In order to be cost effective, systems designed for use on aircraft must be small, lightweight, and conform to the aircraft shape. They also must undergo rigorous and potentially very costly certification if intended for use in safety-critical applications, and must not interfere with other aircraft systems. This is a major challenge in applying satellite communications to the aeronautical communications issues outlined above.

A second major challenge lies in developing the reliability, integrity and security of satellite communications for an aviation environment that requires far higher levels of these qualities than most ground applications. This will be a major psychological hurdle in gaining acceptance of satellite communications for safety critical aeronautical applications. Many years of technology development coupled with flight experiments and demonstrations of increasing complexity will be required.

The NASA Glenn project described in the remainder of this paper is intended to begin the process of addressing the major issues which must be resolved to bring the benefits of satellite communications to bear on the safety and capacity of the future NAS: technology development, system safety, reliability, integrity and security, and experiments and demonstrations of component and system technology.

\section{SYSTEM ARCHITECTURAL APPROACH}

A variety of satellite communications approaches can be applied to aeronautical communications, such as different frequency bands, bandwidths, and antenna system designs. The satellite communications link can then be simply another communications hardware package on the aircraft, in addition to a number of already existing systems. But a real operational and economic gain can be achieved by applying a broadband satellite

communications link to solution to cover a number of applications, thus reducing the total number of systems on the aircraft and mitigating the additional cost. If a satellite communication system of sufficiently broad bandwidth can be installed, services provided to passengers, such as internet connectivity and on-demand video, could actually subsidize the cost of installing new equipment and produce additional revenue. This would help solve a problem of providing an economic incentive for introducing new communications technology into existing aircraft fleets.

For air traffic and safety critical messaging, security, integrity and reliability issues need to be resolved before passenger and safety-related communications could share the same communications equipment. In addition, message latency requirements may need to be considered in using geosynchronous satellite communications links that inherently contain about a one-quarter second round trip delay. However, current requirements for communication link latency will not necessarily apply to the advanced air traffic management methods being considered for the future. But decision support tools and system management algorithms being developed to support future air traffic management must take into account communication link parameters, such as lost or corrupted data packets, network congestion and slowdown, and temporary service interruptions in order to accommodate worst-case situations.

The aeronautical communications architectures being considered for the future take into account different requirements in different aviation operational phases. For example, satellite communication links are more easily applied to en-route phases of flight, where traffic density is lower and the operational decision-making timeframe is longer. In a hybrid space/terrestrial system, the current VHF frequency channels, which do not suffer significant rain attenuation and signal latency, will continue to be the primary communications mode within the terminal area where traffic density is much greater.

The overall data transmission requirements for future air traffic management methods are difficult to determine. A number of competing operational modes exist, ranging from complete aircraft autonomy to centralized, ground-based control of all aircraft. Highly automated decision support and system management algorithms may require very large amounts of aircraft state and intention data, updated very frequently, and significant on-going interaction between aircraft and ground. Operational modes with high degrees of aircraft autonomy will require aircraft-to-aircraft negotiation between all aircraft within a given radius, with the total communications load in a given region growing exponentially with aircraft density. This is an important area of research at the NASA Glenn Research Center. 


\section{KEY TECHNOLOGIES}

Several key satellite communications technologies have been identified for development for aeronautical application. The most important of these is electronically steerable phased array antennas. Other key technologies are fiber-optic signal distribution, fast acquisition modems with optimal coding, and antenna pointing and tracking algorithms.

The phased array antenna is required to electronically establish accurate pointing from the aircraft to the satellite and maintaining that pointing during aircraft movement. AI though a mechanically steered antenna is technically feasible, the electronically steered phased array is preferred because it presents a much lower mechanical profile when mounted on the aircraft, significantly reducing drag and therefore lowering operating cost. In order to maintain a duplex link, both transmit and receive antennas are needed. To enable broadband data rates $256 \mathrm{kbps}$ or more from the aircraft and $2 \mathrm{Mbps}$ or more to the aircraft - antennas of sufficient size and power are needed to create a narrow antenna beam and maintain an adequate link margin. This generally requires more antenna array elements, adding to the cost, size and complexity of the antenna. Using higher frequencies,

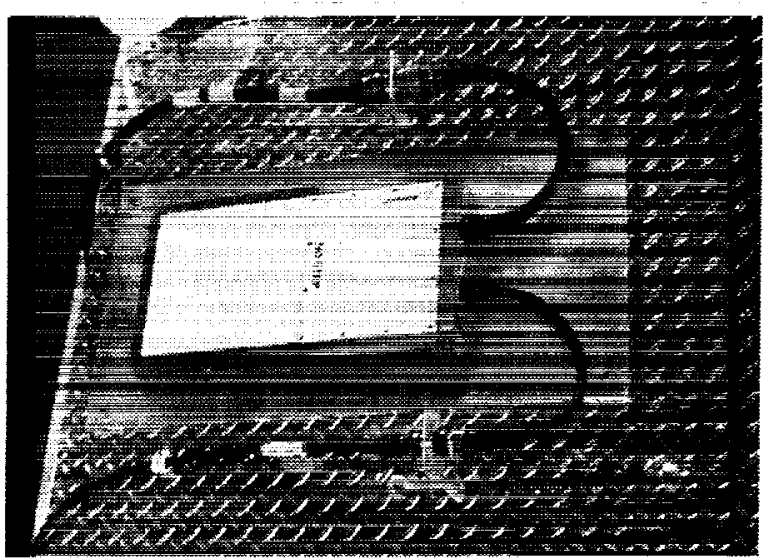

Figure $2-\mathrm{Ku}$ Band transmit phased array antenna.

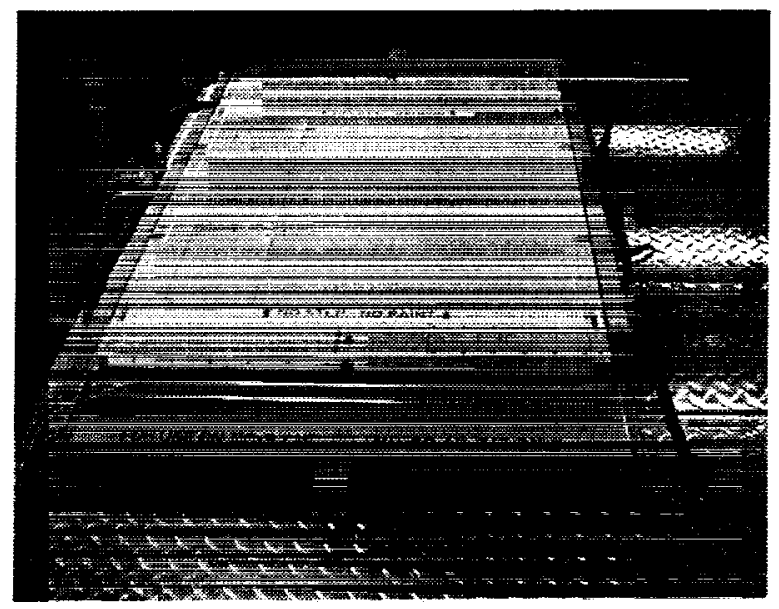

Figure 3-Ku Band receive phased array antenna. such as $\mathrm{Ka}$ Band (20-30 GHz), enables reduced antenna size, but requires more technology development. NASA Glenn has sponsored technology development work, jointly with the U.S. Navy and the Boeing Company, to develop a phased array transmit antenna at $\mathrm{Ku}$ Band $(12 \mathrm{GHz})$. This antenna, and a receive phased array antenna at $\mathrm{Ku} B$ and $(14 \mathrm{GHz})$ which had been previously developed, form the core the NASA Glenn's aero mobile satellite communications terminal described below. These antennas are shown in Figures 2 and 3.

NASA Glenn is also currently co-sponsoring work with the U.S. Navy and the Boeing Company to develop phased array antennas that operate at $\mathrm{Ka}$ Band, and to develop antenna manufacturing processes that will reduce the costs of phased array antennas by at least a factor of ten.

NASA Glenn is performing research and testing into fiber optic signal distribution systems that can provide broadband signal distribution in aircraft. In addition such a system would be able to combine several different types of communications signals from different sources and deliver them to different destinations using a single optical fiber. The fiber optic system would enable signals of much higher bandwidth to be distributed within an aircraft, and the ability to transmit many different signals simultaneously would reduce the number of cables required and also reduce electromagnetic interference. This system is now undergoing laboratory testing.

Modulators and demodulators operating a broadband data rates must be able to acquire the modulated signal carrier as well as signal codes extremely fast in order to maintain a highly reliable system. NASA Glenn is performing and sponsoring research to identify and implement fast acquisition methods, and to determine optimal signal coding schemes for air-to-satellite links. In-house research into improved antenna pointing and tracking control algorithms is also underway. These efforts will feed new technologies into the aeronautical satellite experiment and demonstration program described below.

\section{AERo MOBILE KU BAND SATELlite COMMUNICATIONS TERMINAL AND TESTBED}

In order to perform experiments and demonstrations needed to enable the eventual integration of satellite communications into the aeronautical communications system, the aero mobile satellite communications terminal has been developed. The terminal will be used in ground and air mobile tests during 2000-2004 to demonstrate technologies and system concepts. The terminal is intended to enable an experimental capability, rather than to serve as a model for future aeronautical satellite terminals.

The aero mobile terminal is designed around the $\mathrm{Ku}$ Band phased array antennas that have been developed by Boeing through U.S. Navy and NASA sponsorship. The terminal is capable of connecting to standard data sources and providing transmission of data through any standard commercial $\mathrm{Ku}$ band satellite to any location within the satellite's coverage 
area. The terminal can conversely receive data originating from any location, transmitted through a standard $\mathrm{Ku}$ Band antenna. The size of the antennas allows a nominal transmit data rate of $256 \mathrm{kbps}$ and a nominal receive data rate of $2.048 \mathrm{Mbps}$ through a standard commercial Ku Band satellite transponder.

The terminal uses standard QPSK modems for transmission and reception, and can optionally provide a spread spectrum modulated signal. Frequency up and down converters translate the modem input and output to the phased array antenna operating frequencies.

The aero mobile terminal has been designed to be mounted either in a van for ground mobile experiments or in a NASA research aircraft for air mobile experiments. The ground mobile terminal van, with transmit and receive phased array antennas mounted on top, is shown in Figure 4. In the ground mobile configuration, a gyro system is used to feed inertial navigation information to the antenna controller to enable antenna pointing to be maintained during mobile operations. For the air mobile configuration, connection to the aircraft's inertial navigation system provides the navigation information required for antenna pointing.

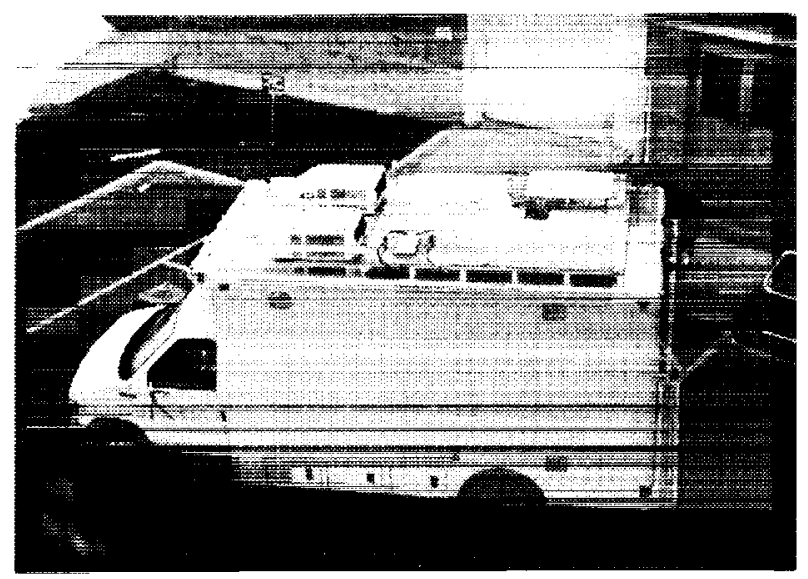

Figure $4-\mathrm{Ku}$ Band aero mobile satellite communications terminal mounted in the ground mobile van.

In conjunction with the aero mobile terminal, a fixed ground testbed is being developed which will enable the creation of realistic test scenarios. The ground testbed will emulate a region of airspace, including the communications occurring between aircraft and ground, so that a ground mobile or air mobile test can be conducted within an air traffic setting adequate to test and demonstrate the performance of the mobile terminal in a system environment. The testbed will include an experiment communications network that can be used to test the performance or air traffic control algorithms that include a satellite link within the information transmission links. This will provide important verification of the ability of satellite communication links to operate within a hybrid aeronautical communications network in a transparent fashion, and enable any real problems with such hybrid networks to be identified and addressed.

\section{EXPERIMENT AND DEMONSTRATION GOALS}

The primary purpose for developing the aero mobile $\mathrm{Ku}$ Band satellite communications terminal and testbed is to provide a test environment for experimental evaluation and demonstration of satellite communications component and system technologies for future aeronautical applications. In addition to evaluating and demonstrating the performance of the satellite communication technologies themselves, the aero mobile terminal is used to demonstrate relevant aeronautical communications applications, such as transmission of air traffic control information, flight information services such as graphical weather imagery, and other air traffic management applications such as traffic information and situational awareness display information. Demonstration of undegraded performance of advanced air traffic control and air traffic management algorithms and decision support software tools is a long-term goal of this facility.

The majority of experiments will take place in the ground mobile configuration. Flight testing is expensive, although necessary to evaluate performance in the high speed, high altitude airborne environment. Flight testing also allows much greater distances to be covered during testing, enabling evaluation of different communication link situations, such as the impact of weather on the link margin. For realistic and convincing demonstrations of satellite communications for airborne applications, only fight test will suffice. However, system functional testing, mobility testing, performance of antenna control performance, testing of application performance all can be accomplished through ground mobile testing.

To summarize, there are three major experiment and demonstration goals:

1. Evaluate and demonstrate the performance of the satellite communications equipment, in a fixed, ground mobile, and air mobile environment.

2. Evaluate and demonstrate the performance of satellite communications links in supporting the operation of relevant aeronautical communications applications.

3. Evaluate and demonstrate the performance of satellite communications links in a hybrid aeronautical communication system/network environment.

\section{EXPERIMENT PLANS AND LATEST RESULTS}

The mobile aeronautical satellite communications experiments and demonstrations will take place during the years 2000 to 2004. During this time, ground mobile experiments will be planned periodically during times in which the mobile terminal is not installed in an aircraft for flight testing. It is anticipated that three to five flight opportunities will occur during the experiment program. 
Initial ground based tests in 2000 are intended to develop and verify the basic functionality of the mobile testbed, including communications hardware performance, communications link performance, and antenna control performance. The initial flight test opportunity, scheduled for December, 2000, will verify these functions in an air mobile environment, and attempt basic application file transfers. Some initial results of the December 2000 flights tests are given below.

During 2001 and 2002, development of relevant aeronautical communications applications will take place. As applications are completed, they will be integrated into the mobile terminal testbed for evaluation and demonstration. The fixed ground testbed will be developed and initial laboratory experiments will occur. By the end of this period, the basic emulation of regional airspace and air traffic test scenarios are expected to be undergoing testing. Ground mobile experiments will continue with gradually increasing levels of complexity. Flight test opportunities will be used to test application performance and integration of the airbome satellite link with the experiment communications network.

During 2003 and 2004, hardware and systems technology development that have been successfully completed will be integrated into the aero mobile terminal. Application development and testing will continue, and increasingly complex applications will be integrated and tested. The development of the fixed ground testbed will continue, and the evaluation demonstration of application performance in a realistic air traffic environment will be the goal as the end of the experiment period approaches. Evaluation of hybrid communications system performance during both ground and air mobile tests will be performed.

Initial aero mobile terminal tests occurred during the summer of 2000 . Functional testing of the system was in a static (non-mobile) mode indicated basic performance of the system. Significant work was required to develop and integrate the gyro-based inertial navigation reference system with the antenna controller. Mobile testing with transmission from a fixed ground transmitter to the ground mobile van was successful, and receive antenna tracking during mobile operations was verified. Coded (Viterbi and Reed-Solomon coding) bit error rate of zero was maintained at data rates up to $2.048 \mathrm{Mbps}$ during mobile operations.

\section{RECENT FLIGHT TESTS ON THE NASA DRYDEN RESEARCH CENTER DC-8}

At the time of final preparation of this paper, initial flight tests have been initiated and the first results observed. The aero mobile terminal was installed in a NASA experiment aircraft DC-8 operated at the NASA Dryden Flight Research Center at Edwards Air Force Base, California. During several flight tests at altitudes up to
40,000 feet, successful operation of the aero-mobile terminal in a duplex communication mode was established. Transmit data rates (from the aircraft through the $\mathrm{Ku}$ Band satellite to the earth station at NASA Glenn) of $256 \mathrm{kbps}$ were achieved. Receive data rates (from NASA Glenn through the satellite to the aircraft) of $2.048 \mathrm{Mbps}$ were achieved. Several basic communications network applications, including e-mail sending and receiving, Internet web browsing, and voice-overIP were tested simultaneously and performed very well. The first initial tests of aeronautical telecommunications network (ATN) over broadband satellite included the transmission of Controller Pilot Data Link Communications application messages, which were also transmitted successfully. The DC8 flight tests are continuing, and the terminal and phased array antenna performances will be characterized, as well as additional communications applications.

\section{SUMMARY}

The NASA Glenn Research Center is engaged in research and development of satellite communications technologies for aeronautical applications, in support of NASA's goals for increasing the capacity and improving the safety of the National Airspace System. The NASA Glenn program consists of development of key aeronautical satellite communications technologies and the evaluation and demonstration of aeronautical satellite communication component and system technologies, with the goals of obtaining adequate technical performance and fostering the eventual acceptance and deployment of satellite communications as part of the aeronautical communications system.

NASA Glenn has co-sponsored the development of Ku Band transmit phased array antennas and is actively working on other key technologies. The Ku Band transmit phased array, together with a receive phased array antenna, are the basis for an aero mobile satellite communications terminal and testbed. The terminal and testbed are being used in a series of ground and air mobile experiments and demonstrations. These experiments and demonstrations will evaluate and demonstrate the performance of satellite communications equipment, the performance of aeronautical applications over satellite links, and the performance of satellite links within a hybrid aeronautical communications system. The initial flight tests in December, 2000 established successful duplex communications operation of the aero mobile terminal and demonstrated both IP and ATN network based communications through satellite from an operating aircraft.

\section{REFERENCES}

[1] NASA Aviation System Capacity Program, http://www.asc.nasa.gov/

[2] NASA Aviation Safety Program, http://avsp.Iarc.nasa.gov/

[3] FAA National Airspace System Architecture Version 4.0, $\mathrm{http}: / / \mathrm{www}$. faa.gov/nasarchitecture/version $4 . \mathrm{htm}$ 
[4] NASA Advanced Air Transportation Technologies (AATT) Program Free Flight Satellite Communication Study, Final Report, Lockheed Martin Aeronautical Systems, for NASA Glenn Research Center, August, 1998.

[5] Communications System Architecture Development For Air Traffic Management \& Aviation Weather Information Dissemination, NASA Research Task Order 24, Final Report, Science Applications International Corporation, for NASA Glenn Research Center under Contract NAS2-98002, May, 2000.

Robert J. Kerczewski has been involved with research and development of satellite communications systems and applications since 1982, for the Analex Corporation and NASA. He holds a BEE degree from Cleveland State University (19S2) and an MSEE degree from Case Western Reserve

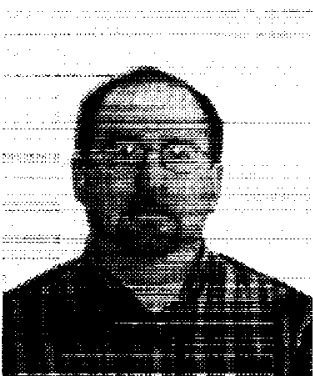
University (1987). At NASA, he has managed the High Burst Rate Interference Experiment, Advanced Space Communications Laboratory, and Telemammography Using Satellite Communications Project. He is currently the Project Manager for the Advanced Communications for Air Traffic Management element of NASA's Advanced Air Transportation Technologies (AATT) Project.

216-433-3434,rkerczewski@grc.nasa.gov

Douglas J. Hoder has been involved with design and enginecring $R F$ communcations sistems for the last seventeen years. He has worked in the militan electronics, television and cellular phone industries for the Georgia Tech Research Institute, Scientific-Atlanta and Motorola, Inc. He is the

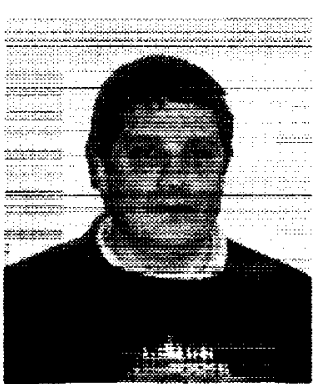
co-inventor on several US and foreign patents. He holds degrees from the Cleveland State University, in Cleveland, OH, (BEE, 1983) and the Georgia Institute of Technology, in Atlanta, GA (MSEE, 1986). He has been with NASA Glenn since 1990. At NASA, he managed the development of the Gigabit Satellite Network, and served as Project Engineer for the ACTS High Data Rate Program. His current work involves high performance $R F$ communications for air transport.

216-433-3438,Douglas.J.Hoder@grc.nasa.gov
Robert J. Zakrajsek has been involved with design and engineering of Telemetry, Antenna, and $R F$ communications systems at NASA for the last thirty seven years. He holds a BSEE degree from the Ohio University, in Athens, $\mathrm{OH}$, (1963). He has been with NASA Glenn since 1963. Where he managed the Microwave Systems

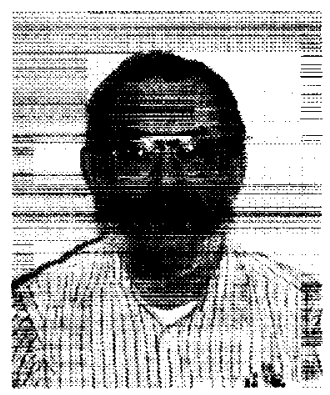
Laboratory and served as Project Engineer for the Sert II, ASDAR, Sphinx, and Aero-X Programs. His current work involves both Weather Information Communications for Aviation Safety and high performance communications for air transport.

216-433-3487,Robert.J.Zakrajsek@lerc.nasa.gov 


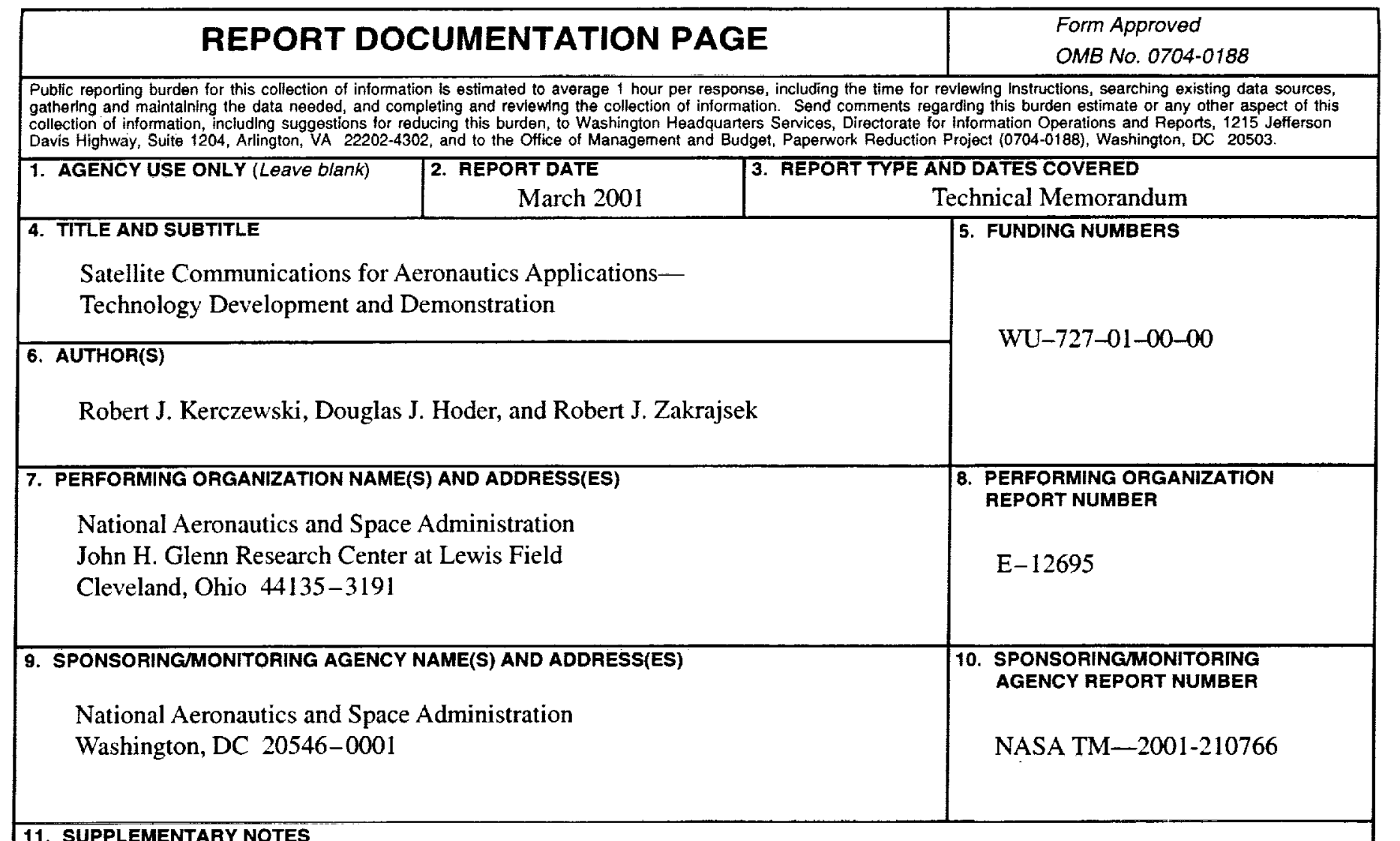

Prepared for the 2001 Aerospace Conference sponsored by the Institute of Electrical and Electronics Engineers, Big Sky, Montana, March 10-17, 2001. Responsible person Robert J. Kerczewski, organization code 6150, 216-433-3434.

128. DISTRIBUTION/AVAILABILITY STATEMENT

Unclassified - Unlimited

Subject Category: 04

Distribution: Nonstandard

Available electronically at http//gltrs.grc,nasa.gov/GLTRS

This publication is available from the NASA Center for AeroSpace Information, 301-621-0390.

13. ABSTRACT (Maximum 200 words)

The National Aeronautics and Space Administration (NASA) is performing research and development to improve the safety and increase the capacity of the National Airspace System (NAS). Improved communications, especially to and from the aircraft flight deck, has been identified as an essential enabling technology for future improvements to the air traffic management system and aviation safety. NASA's Glenn Research Center is engaged in research and development of satellite communications technologies for aeronautical applications. A mobile aero terminal has been developed for use with $\mathrm{Ku}$ band commercial communications satellites. This experimental terminal will be used in mobile ground and air-based tests and demonstrations during 2000-2004. This paper will describe the basic operational parameters of the Ku Band aero terminal, the communications architecture it is intended to demonstrate, and the key technology issues being addressed in the tests and demonstrations. The design of the Ku Band aero terminal and associated ground testbed, planned tests and demonstrations, and results to date will be presented.

\section{SUBJECT TERMS}

Satellite communications; Aeronautical communications

\begin{tabular}{|c|c|}
\hline $\begin{array}{c}\text { 17. SECURITY CLASSIFICATION } \\
\text { OF REPORT }\end{array}$ & $\begin{array}{c}\text { 18. SECURITY CLASSIFICATION } \\
\text { OF THIS PAGE } \\
\text { Unclassified }\end{array}$ \\
Unclassified \\
\hline
\end{tabular}

19. SECURITY CLASSIFICATION
OF ABSTRACT
Unclassified
Unclassified 